\title{
Fuzzy modeling in human resource management
}

\author{
Mykola Ivanov*, Sergey Ivanov, Nataliia Terentieva, Victoria Maltiz, and Julia Kalyuzhnaya \\ Zaporizhzhia National University, 66 Zhukovsky Str., Zaporizhzhia, 69063, Ukraine
}

\begin{abstract}
This article discusses the theoretical aspects of evaluating personnel performance indicators in the development of the digital economy. Eight procedures were identified for a comprehensive assessment of staff performance. A mathematical apparatus was built for assess normative or average values of performing job duties, determine many specialties, assess the level of education, evaluate the levels of enterprise management, describe many posts, describe the correspondence and interchangeability of posts, evaluate additional characteristics of employees and describe many additional tasks and their characteristics. Allocated linguistic variables characteristics of employees. The structural model of data mining in HR process management was built. Highlighted the membership function of the input linguistic variables of the staff and conducted a description of linguistic variables.
\end{abstract}

\section{Introduction}

Today, business is forced to solve a whole range of complex and unique tasks. So, to solve the problems of increasing and stabilizing the management of economic facilities in modern conditions, new approaches and solutions are required, which determined the emergence of a new concept of the German economist Klaus Schwab, President of the World Economic Forum in Davos [1]. According to this concept, it is stated that we live in the era of the fourth industrial revolution, where the virtual world is combined with the physical world using information technology. The fourth industrial revolution is characterized by a change in economic relations and the widespread use of intelligent technologies (Cloud technologies, Big Data, artificial neural networks and fuzzy sets, data mining and others), which is the basis of the digital economy.

It should be noted that there are various approaches to the determination and measurement of the dynamics of the digital economy, and it is also difficult to assess its volume. According to estimates (https://www.emarketer.com/topics/topic/b2b), the share of the digital segment of the global economy in 2020 could be $23 \%$ ( $\$ 17$ trillion). This leads to the expansion and rapid development of the Internet market using Big Data, followed by modeling by fuzzy logic approaches.

Therefore, for successful management of economic facilities in the digital economy an important role is given to HR management systems (Human resources) which are able to offer a radically new mechanism that allows companies to remain competitive in the market.

The first direction is determined by the level of application of intelligent systems. High information technologies embrace the world and replace the classical methods of HR-process management. Robot programs are now being applied, offering employees of the enterprise to undergo an express interview or interview using yet expert systems.

The next direction is the analysis and evaluation of young professionals who are able to learn and solve modern problems. Now, new specialists up to 25 years of age who have completely different knowledge, interests and fundamentally different ideas about modern work are entering the labor market. Young specialists are able to quickly make managerial decisions and push new projects forward, and thereby increase the level of work in the enterprise.

In addition to these areas, it should be noted that for a long time HR management was aimed at standardization and versatility. However, this approach is gradually becoming obsolete today. This approach is being replaced by HR management methods that are focused on the maximum use of the intellectual capital of employees. This is stimulated with the simultaneous satisfaction of individual needs, desires, employee capabilities and their synchronization with the tasks of the enterprise. Modern HR specialists are beginning to more closely monitor the development of employees within the enterprise, which allows flexible management of career growth, which can be adjusted taking into account the proposals of the employees themselves.

\section{Formal problem statement}

HR strategy is part of the overall strategy of enterprises and long-term planning of their business activities. An important role in these plans is played by assessments of the degree of personnel efficiency as a factor in updating and increasing production efficiency in the overall economic strategy of an enterprise. The creation of

\footnotetext{
* Corresponding author: nn iva@ukr.net
} 
modern catalogs of employee data and their management requires the processing of a large amount of information. This is due to a wide range of organizational, economic and technical and technological tasks that are performed by personnel. Therefore, data analysis in the management of HR processes is an urgent task.

\section{Literature review}

The influence of information technology in the management of economic systems was presented in the work of S. Ivanov [2]. However, the problems of rating management have not been resolved. The solution to the problem of rating management was the work of Yu. Lysenko, V. Petrenko [3]. However, the level of staff development and their assessment were not considered. This work was devoted to the solution of this problem, in which the theoretical aspects of personnel development are studied, in particular, the concept, main tasks and directions of personnel development at the enterprise. V. Helman [4] considers the development of enterprise personnel as a change in its qualitative characteristics, in which indicators in the form of degree of activity were proposed.

Human resource management as a strategic human resource management today is seen as going beyond the boundaries of management tasks, such as motivation, the level of remuneration. Instead, managers need to consider HR management as a process that contributes to the success of the enterprise. Therefore, the work of Brian E. Becker [5] considers approaches where all managers should be involved in the management process, where the role of employees is important for the competitive advantage of the enterprise. In addition, organizations that value their skilled employees are more profitable than those that do not. Mark A. Huselid [6], Jeffrey Pfeffer and John F. Veiga [7]. The results of the work show that successful enterprises have several common characteristics: stable job security, the use of self-government methods, perfect pay and access to information. These tasks were considered in the work of Brian E. Becker, Mark A. Huselid [8], when an enterprise develops and motivates the development of human capital. The most successful enterprises manage $\mathrm{HR}$ as a strategic asset, and evaluate the effectiveness of labor resources in terms of its impact. When each employee of the enterprise effectively fulfills his duties and creates a high-performance work system in which the employee has the maximum involvement and responsibility of Dennis R. Briscoe [9].

In modern enterprises, an important task is to ensure a balance between the need for coordination and synchronization of units located both in different cities and around the world, which was reviewed by Randall S. Schuler, Pawan S. Budhwar, and Gary W. Florkowski [10]. Achieving this balance is becoming increasingly difficult as the level of functional diversity to which enterprises are exposed increases.

Today, new intelligent technologies are emerging to solve these problems. Such intelligent technologies include research and project management recommendations. Such works include the works of S. Gottwald [11].

These projects on improvement of resource processes are the ones of the most important tasks of production in enterprise management. Currently, the number of works in this direction is increasing by the D. Mukhamediyeva [12] and W. Siler, J. Buckley [13]. The obvious advantage of the proposed methods is the use of mathematical tools, the theory of fuzzy sets, which allows implementing the process of selecting conditions, the introduction of the method in the managerial processes of the enterprise. It should be noted that this work did not solve the problem of data mining in HRprocess management with the possibility of modeling the degree of personnel efficiency, which determined the topic and relevance of this article.

\section{The purpose of the article}

The article is devoted to the analysis of the level of staff performance. The process of determining new, corrective, and available useful knowledge based on the theory of fuzzy sets.

\section{Modelling HR-management}

The task of fuzzy modeling and data mining when managing HR processes is to efficiently extract and analyze the existing data array of employees with subsequent management of personnel using cloud solutions. This will allow the rapid implementation of a new personnel management system, obtaining a new level of accessibility and increasing its mobility.

The resulting performance indicators of personnel at the enterprise can be represented in the form of multidimensional structures, where each measurement is represented by the corresponding indicators of the enterprise management system.

The following method of modeling human resources is proposed, which is presented in Fig. 1.

The proposed method includes four stages. The first stage solves the problem of choosing the analyzed indicators. For this, a lot of ratings are determined:

$$
P=\left\{p_{i}=(o p 1, o p 2, e p 1, e p 2, e p 3)\right\}, i=\overline{1, N},
$$

where $o p 1$ is a generalized indicator of job compliance, characterizing the degree of conformity of qualifications and work experience of the post, level of responsibility, as well as the quality of the performance of current work and duties,

op2 - a generalized indicator of diligence, characterizing the effectiveness of the tasks (complexity, quality, timeliness),

ep 1 - ambitiousness, a single indicator of personality characteristics,

ep 1 - the quality of a leader, an indicator of personality characteristics,

ep3 - the level of attitude in the team, a single indicator of personality characteristics. 


\begin{tabular}{|c|c|c|}
\hline 2 Stage & 3 Stage & $\begin{array}{c}4 \text { Stage } \\
3 \\
3\end{array}$ \\
\hline $\begin{array}{l}\text { The procedures: } \\
\text { I- assessment of normative or average } \\
\text { values of job performance, } \\
\text { II- the definition of many specialties, } \\
\text { III- assessment of the level of education, } \\
\text { IV- assessment of enterprise management } \\
\text { levels, } \\
\text { V- description of many posts, } \\
\text { VI- a description of the conformity and } \\
\text { interchangeability of posts, } \\
\text { VII- assessment of additional }\end{array}$ & $\begin{array}{l}\text { The procedure } \\
\text { for assessing the } \\
\text { conformity of } \\
\text { the specialty of } \\
\text { the position. }\end{array}$ & $\begin{array}{l}\text { The procedures: } \\
\text { I- construction of } \\
\text { membership functions, } \\
\text { II- finding a clear value } \\
\text { for each of the input } \\
\text { linguistic variables, } \\
\text { III- construction of } \\
\text { the diligence function of } \\
\text { the output linguistic } \\
\text { variable. }\end{array}$ \\
\hline
\end{tabular}

Fig. 1. The method of modeling human resources in fuzzy management.

At the second stage, the initial information is determined, which is necessary for calculating indicators based on expert assessments, analytical indicators (for example, work experience, quality of work performed, and others).

To describe the formalized set of sets of source information, we introduce the rules, namely, if the set $P=\left\{p_{i}=(o p 1, o p 2, o p 3)\right\}$, is defined, then to use the value of the component op02 of unit level 0 , we will use the notation op 2 (join operator)

At the second stage, procedures are applied that allow:

The first (I) procedure allows you to evaluate the regulatory or average value of the performance of official duties by employees $-P 0$ :

$$
\mathrm{P} 0=\left\{\mathrm{p} 0_{\mathrm{i}}=(\mathrm{op} 01, \mathrm{op} 02)\right\}, \mathrm{i}=\overline{1, \mathrm{~N}},
$$

where op01 normative or average value of the job performance of the $i$-th employee,

op 02 - normative or average value of the level of assessment of the performance of tasks of the $i$-th employee.

The second (II) procedure is aimed at identifying many specialties (economist, programmer, builder and others) - SP:

$$
S P=\left\{s p_{r}\right\}, r=\overline{1, L^{s p}},
$$

where $s p_{r}$ - is the $r$ - th specialty,

$L^{s p}$ - is the number of specialties.

The third procedure allows you to assess the level of education (secondary, bachelor, master and others) $-U O$ :

$$
\mathrm{UO}=\left\{\mathrm{uo}_{\mathrm{v}}=(\text { name }, \mu\}, \mathrm{v}=\overline{1, \mathrm{~L}^{\mathrm{uo}}},\right.
$$

where $u o_{v}$ - is the vector of characteristics of the $v$-th category,

name - category name,

$\mu$ - assessment of the level of education for the category in points,

$L^{u o}$ - is the number of categories.
The fourth (IV) procedure is aimed at assessing the level of enterprise management (higher, middle and lower level) $-U D$ :

$$
\mathrm{UD}=\left\{\mathrm{ud}_{\mathrm{w}}=(\text { name }, \gamma)\right\}, \mathrm{w}=\overline{1, \mathrm{Lud}^{\mathrm{ud}}},
$$

where $u d_{w^{-}}$is the vector of characteristics of the $w$-th level,

name - level name,

$\gamma-$ is an estimate of the level in points,

$L^{u d}$ - the number of levels, which is determined by the scale of the enterprise.

The fifth (V) procedure solves the problem of describing many positions in the enterprise $-D$ :

$$
\begin{aligned}
& \mathrm{D}=\left\{\mathrm{d}_{\mathrm{j}}=(\text { name, } \mathrm{ud}, \mathrm{uo}, \mathrm{kl}, \mathrm{SPD}): \mathrm{ud} \in \mathrm{UD}, \mathrm{uo} \in\right. \\
& \mathrm{UO}\}, \mathrm{j}=\overline{1, \mathrm{~L}^{\mathrm{d}}} \text {, } \\
& \mathrm{SPD}=\left\{\operatorname{spd}_{\mathrm{r}}=(\mathrm{sp}, \beta): \mathrm{sp} \in \mathrm{SP}, 0 \leq \beta \leq 1\right\}, \mathrm{r}= \\
& 1, \mathrm{~L}_{\mathrm{j}}^{\mathrm{spd}} \text {, }
\end{aligned}
$$

where $d_{j}$ is the $j$-th position,

name - job title,

$u d$ - position level in the organizational and staff structure of the enterprise,

$u o$ - the level of education required for the $j$-th position,

$k l$ - required work experience (minimum number of years) in a given position for an optimal qualification level,

$S P D$ - many specialties related to this position,

$s p d_{r}$ is the vector of the correspondence characteristics of the $r$-th specialty of the $j$-th position $\beta$,

$\beta-$ is the correspondence coefficient of the specialty sp of the $j$-th position,

$L^{d}-$ is the number of posts,

$L_{j}^{s p d}$ - number of specialties in the $j$-th position.

The sixth (VI) procedure solves the tasks of describing correspondence and job interchangeability $S D$ : 


$$
\begin{array}{r}
\mathrm{SD}=\left\{\mathrm{sd}_{\mathrm{f}}=(\mathrm{d} 1, \mathrm{~d} 2, \alpha): \mathrm{d} 1 \in \mathrm{D}, \mathrm{d} 2 \in \mathrm{D} 0 \leq \alpha \leq\right. \\
1, \forall(\mathrm{d} 1=\mathrm{d} 2) \Rightarrow \alpha=1\}, \mathrm{f}=\overline{1, \mathrm{~L}^{\text {sd }}}, \\
\mathrm{L}^{\text {sd }}=\left(\mathrm{L}^{\mathrm{d}}\right)^{2},
\end{array}
$$

where $s d_{f}-$ is the $f$-th vector of job matching characteristics $d 1$ and $d 2$,

$\alpha-$ is the compliance coefficient.

The seventh (VII) procedure is aimed at assessing additional characteristics of employees $-A$ :

$$
A=\left\{a_{i}=(d s, S T, O B): d s \in D, u o \in U O\right\}, i=\overline{1, N},
$$

$$
\begin{aligned}
& \mathrm{ST}=\left\{\mathrm{st}_{\mathrm{j}}=(\mathrm{d}, \mathrm{kL}): \mathrm{d} \in \mathrm{D}, \mathrm{d} \in \mathrm{UO}\right\}, \mathrm{j}=\overline{1, \mathrm{~L}_{1}^{\mathrm{st}}}, \\
& \mathrm{OB}=\left\{\mathrm{ob}_{\mathrm{w}}=(\mathrm{sp}, \mathrm{uo}, \mathrm{god}): \mathrm{sp} \in \mathrm{SP}, \mathrm{uo} \in \mathrm{UO}\right\}, \mathrm{w}= \\
& \overline{1, \mathrm{~L}_{1}^{\mathrm{ob}}},
\end{aligned}
$$

where $a_{i}-$ is the vector of characteristics of the $i$-th employee,

$d s-$ the position held by the employee,

$S T$ - many posts in which the employee previously worked and experience in them,

$s t_{j}$ - vector of characteristics of work experience in previous positions,

$k L$ - length of service (number of years) in the position $d$,

$O B$ - value, reflects the education received by the $i$-th employee; $s p$ - specialty; $u o$ - level of education,

god - year of receipt of the qualification document (certificate, certificate, diploma and others),

$L_{i}^{s t}$ - the number of posts previously held by the $i$-th employee,

$L_{i}^{o b}$ - the number of specialties in which the employee was educated by the $i$-th employee.

The eight (VIII) procedure allows you to describe many additional tasks (determined by orders) and their characteristics in the enterprise:

$$
Z=\left\{\mathrm{z}_{\mathrm{k}}=\left(\mathrm{t} 0, \mathrm{tk}, \mathrm{tk}^{\prime}, \mathrm{usz}\right), 0 \leq \beta \leq 1\right\}, \mathrm{k}=\overline{1, \mathrm{M}},
$$

where $z_{k}-$ is the vector of characteristics of the $k$-th task,

$t 0$ and $t k$ - the value of the beginning and end of tasks, determines the term for completing the task in units of measurement of working time (for example, working days, hours and others),

$t k^{\prime}$ - the value of time, determines the critical deadline for completing the task, after which the task is either canceled or transferred to another performer,

usZ - task difficulty level,

$M$ is the number of tasks.

The set of completing additional IZ tasks by employees can be written as follows:

$$
\begin{array}{r}
\mathrm{IZ}=\left\{\mathrm{iz}_{\mathrm{k}}=\left(\mathrm{a}, \mathrm{z}, \mathrm{uv}^{\mathrm{p}}, \mathrm{uv}\right): \mathrm{a} \in \mathrm{A}, \mathrm{z} \in \mathrm{Z}, 0 \leq \mathrm{uv}^{\mathrm{p}} \leq\right. \\
200\}, \mathrm{k}=\overline{1, M},
\end{array}
$$

where $i z_{k}$ is the characteristic of the $k$-th job,

$a$ - an employee who performs additional tasks,

$z$ - the task

$u v^{p}-$ is the percentage of the task according to the plan at the current time $t\left(u v^{p}=0\right.$ at time $t 0$, $u v^{p}=200$ at time $k$ ),

$u v$ - is the percentage of the task at the current time $t$.

In case of failure to perform additional tasks, the value of $I Z=0$.

At the third stage, the procedure for assessing the conformity of the specialty of the position is performed. The function $f \beta$ returns the value of the correspondence of the specialty xsp to the position $\mathrm{xd}$ :

$$
\begin{gathered}
\mathrm{f} \beta(\mathrm{xsp}, \mathrm{xd})= \\
\left\{\begin{array}{c}
\mathrm{d}_{\mathrm{j} 0} \cdot \mathrm{spd}_{\mathrm{i} 0} \cdot \beta, \exists \mathrm{j}_{0}, \mathrm{r}_{0}:\left(\mathrm{d}_{\mathrm{j} 0}=\mathrm{xd}\right) \wedge\left(\mathrm{d}_{\mathrm{j} 0} \cdot \operatorname{spd}_{\mathrm{r} 0} \cdot \mathrm{sp}=\mathrm{xsp}\right) \\
0, \neg \exists \mathrm{j}_{0}, \mathrm{r}_{0}:\left(\mathrm{d}_{\mathrm{j} 0}=\mathrm{xd}\right) \wedge\left(\mathrm{d}_{\mathrm{j} 0} \cdot \mathrm{spd}_{\mathrm{r} 0} \cdot \mathrm{sp}=\mathrm{xsp}\right)
\end{array}\right.
\end{gathered}
$$

The function $f \alpha$ returns the value of the coefficient of correspondence and interchangeability of the post xsp post xd:

$$
\begin{gathered}
f \alpha(x d s, x d)= \\
\left\{\begin{array}{c}
\operatorname{sd}_{\mathrm{g}} \alpha, \exists \mathrm{g}_{0}:\left(\operatorname{sd}_{\mathrm{g} 0} \cdot \mathrm{d} 1\right) \wedge\left(\operatorname{sd}_{\mathrm{g} 0} \cdot \mathrm{d} 2=\mathrm{xd}\right) \\
0, \neg \exists \mathrm{g}_{0}:\left(\operatorname{sd}_{\mathrm{g} 0} \cdot \mathrm{d} 1\right) \wedge\left(\operatorname{sd}_{\mathrm{g} 0} \cdot \mathrm{d} 2=\mathrm{xd}\right)
\end{array}\right.
\end{gathered}
$$

To determine job conformity is the level of education of the position held in conjunction with work experience in similar or related positions:

$$
\begin{gathered}
p_{i} . o p 1=\delta(o p 11 \cdot o p 12) \cdot o p 13, \\
o p 11=\sum_{w=1}^{L_{i}^{o b}} f \beta\left(a_{i} \cdot o b_{w} . s p, a_{i} . d s\right) \cdot \frac{a_{i} \cdot o b_{w} \cdot g o d}{g o d T}, \\
o p 12=\sum_{j=1}^{L_{i}^{s t}} f \delta\left(a_{i} \cdot d s . f, a_{i} \cdot s t . d\right) \cdot \frac{a_{i} \cdot s t_{j} \cdot k L}{a_{i} \cdot d s . k L}
\end{gathered}
$$

where $\operatorname{god} T$ - is the value of the current year,

op 11 - qualification level of education received,

op 12 - qualification level, which is determined by work experience,

op 13 - quality of job performance, determined by an expert.

When solving the problem of data mining in the management of HR processes, fuzzy logic methods are used to display the result on the interval $[0 ; 1]$.

Therefore, at the fourth stage, the procedure for constructing membership functions based on the theory of fuzzy sets is performed.

The following "position", "level", "education" can be attributed to numerical linguistic variables of employees, and "conflict", "level of substitution" to linguistic variables. Numerical linguistic variables and their meanings serve for a qualitative description of a quantitative quantity. The values of linguistic variables are determined by experts.

It should be noted that a linguistic variable, like its original term set, is associated with a specific dimensional scale on which all arithmetic operations are defined.

To assess the characteristics of employees in table 1, linguistic variables and their dimensions are proposed.

The use of the concept of stimulation and destimulation is applied taking into account the influence on the degree of personnel efficiency, namely, 
stimulation - the effect on the increase and destimulation - on the reduction of the factor.

Table 1. The linguistic variables of employee characteristics.

\begin{tabular}{|c|c|c|c|c|}
\hline Term set & $\begin{array}{c}\text { The metric and type of } \\
\text { exposure }\end{array}$ & $x_{\text {min }}^{1}$ & $x_{\text {max }}^{1}$ & \begin{tabular}{|c|} 
The term \\
designation
\end{tabular} \\
\hline $\begin{array}{c}T_{1}^{1}=\cup T_{1}^{j} \\
j=\overline{1,3}\end{array}$ & $\begin{array}{l}\text { Performance of duties } \\
<\text { position }>- \\
\text { stimulation }\end{array}$ & 0 & 1 & $\begin{array}{l}\text { Not } \\
\text { performed } \\
\text { Partially } \\
\text { completed } \\
\text { Performed }\end{array}$ \\
\hline $\begin{aligned} T_{2}^{1} & =\cup T_{1}^{j} \\
j & =\overline{1,3}\end{aligned}$ & $\begin{array}{l}\text { Job Interchangeability } \\
<\text { Interchangeability } \\
\text { Level }>\text {, discouragement }\end{array}$ & 1 & 3,0 & \begin{tabular}{|l} 
Low \\
Average \\
High \\
\end{tabular} \\
\hline $\begin{aligned} T_{3}^{1} & =\cup T_{1}^{j} \\
j & =\overline{1,3}\end{aligned}$ & $\begin{array}{l}\text { Level of education } \\
<\text { education }>\text {, } \\
\text { stimulation }\end{array}$ & 1 & 3,0 & $\begin{array}{l}\text { Secondary } \\
\text { education } \\
\text { Bachelor } \\
\text { Master }\end{array}$ \\
\hline $\begin{aligned} T_{4}^{1} & =\cup T_{1}^{j} \\
j & =\overline{1,3}\end{aligned}$ & $\begin{array}{l}\text { Conflict <conflict>, } \\
\text { stimulation }\end{array}$ & 0 & 3,0 & $\begin{array}{l}\text { Low } \\
\text { Average } \\
\text { High } \\
\end{array}$ \\
\hline $\begin{aligned} T_{5}^{1} & =\cup T_{1}^{j} \\
j & =\overline{1,3}\end{aligned}$ & $\begin{array}{l}\text { The importance level of } \\
\text { the specialty } \\
<\text { SpecialtyLevel }>\text {, } \\
\text { discouragement }\end{array}$ & 0 & 0,5 & $\begin{array}{l}\text { Low } \\
\text { Average } \\
\text { High }\end{array}$ \\
\hline
\end{tabular}

Therefore, the term set $T_{i}^{n}=\left\{T_{i}^{n \prime}\right\}$ is associated with the set $T_{i}^{n \prime}$, where $T_{i}^{n \prime}=\left\langle x, \mu_{T_{i}^{n \prime}}(x) / x \in\left[x_{\text {min }}, x_{\text {max }}\right]\right\rangle$ is a fuzzy number, $i=\overline{1, m}, m$ is the number of term sets, $n$ is the number of employees.

To eliminate the influence of changes in the input variables of the metrics and, as a consequence, the correction of term sets, a transition to a normalized function is proposed. Let the previously defined term set $T_{i}$ be the original one.

The normalized linguistic variable is a mapping on the interval $[0 ; 1]$ :

$$
D_{i}^{n}=\left\{D_{i}^{n \prime}\right\}, D_{i}^{n \prime}=\left\langle z, \mu_{D_{i}^{\prime}}(z) / z \in[0,1]\right\rangle,
$$

where $z$ is a fuzzy number corresponding to the term set $D_{i}^{\prime}$ on the interval $[0 ; 1], n$ is the number of employees.

These functions allow you to display heterogeneous input variables in a single normalized interval $[0 ; 1]$, which allows you to reduce errors associated with different quantities and their dimensions. This provides a convenient representation of the values, as well as their interpretation.

The structural model of data mining in HR process management is presented in Fig. 2.

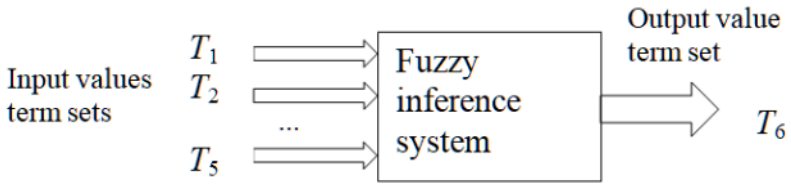

Fig. 2. The structural model of the model of data mining in the management of HR-process.

In the structural model, $T=\{T i\}$ is a term set, where $i=\overline{1, n}, n$ is the number of sets, each of which is represented by a fuzzy variable with a domain of definition $X$.
The process of modeling fuzzy values is based on a fuzzy inference system, which allows you to convert expert estimates into fuzzy values.

In the fuzzy inference system, the procedure for finding a clear value for each of the input linguistic variables based on defuzzification is applied. Defuzzification in a fuzzy inference system is the process of finding a value for each of the output linguistic variables of the set $W=\left\{x_{1}, x_{2}, \ldots x_{n}\right\}$. The task of defuzzification is that using the results of accumulation of all output linguistic variables, it is necessary to obtain a quantitative value of each of the output variables, which can be used in a fuzzy inference system relative to the input linguistic variable.

Under the accumulation of fuzzy inference is understood the process of finding the membership function for each of the output linguistic variables of the set.

Thus, the transformation of a fuzzy set into some specific values of variables, namely, leading to clarity is defuzzification.

The defuzzification procedure is performed by a sequence that considers each of the output linguistic variables $\beta$ and the fuzzy set $T_{i}=\left\{T_{i}^{j}\right\}$ related to it. The result of defuzzification for the output linguistic variable is defined as a quantitative value.

The defuzzification process is considered complete when quantitative values are determined for each of the output linguistic variables. For the fuzzy inference system, the Mamdani algorithm was applied.

The Mamdani algorithm includes the following steps: 1) the formation of a rule base for fuzzy inference systems;

2) fuzzification of input variables;

3) aggregation of conditions in fuzzy rules to find the degree of truth of the conditions of each of the rules of fuzzy logic;

4) accumulation of conclusions of fuzzy production rules;

5) defuzzification of output variables based on the center of gravity method.

Depending on the nature of the domain $X$, numerical linguistic variables can be defined.

The values of linguistic variables are determined on an ordinal scale. It should be noted that a linguistic variable, like its original term set, is associated with a specific scale on which all arithmetic operations are defined. Therefore, the term set $T_{i}=\left\{T_{i}^{j}\right\}$ is associated with the set $T_{i}^{j}$, where $T_{i}^{j}=\left\langle x, \mu_{T_{i}^{j}}(x) / x \in\right.$ $\left.\left[x_{\text {min }}, x_{\text {max }}\right]\right\rangle, \quad i=\overline{1, n} ; j=\overline{1, m} ; n$ is the number of term sets, $m$ is the number of terms.

A model that satisfies these fuzzy sets is their union:

$$
\mu T_{i}=\sup \left(\mu_{T_{i}^{j}}(x)\right), T_{i}=\cup T_{i}^{j} .
$$

We construct membership functions for the linguistic variable characteristics of employees, presented in table 1.

The process of converting experts' qualitative assessments into fuzzy quantities consists in mapping the 
elements of the original term set in the form of constructing membership functions of fuzzy quantities $T_{i}^{j} \in T_{i}$.

The description of linguistic variables is as follows:

〈position, \{not fulfilled, partially fulfilled, fulfilled\}, $[0 ; 1]\rangle$,

$\langle$ level of interchangeability, \{low, medium, high\},

$[1 ; 3]\rangle$,

$\langle$ education, \{secondary, bachelor, master\}, [1;3]〉,

$\langle$ conflict, \{low, medium, high\}, [1; 3] $\rangle$.

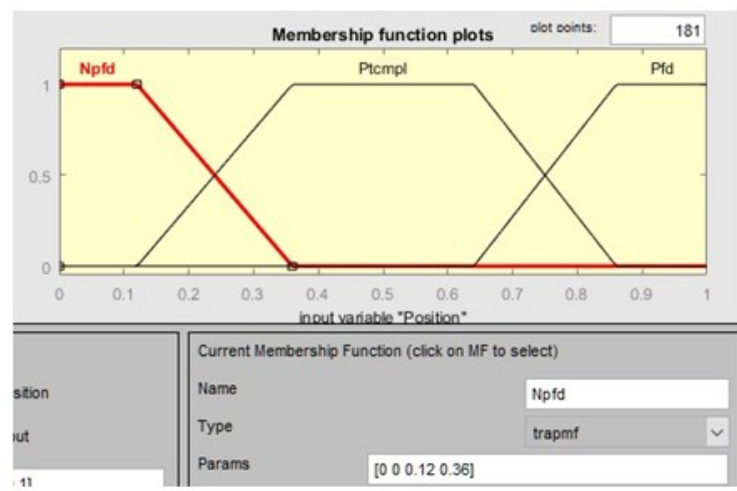

a)

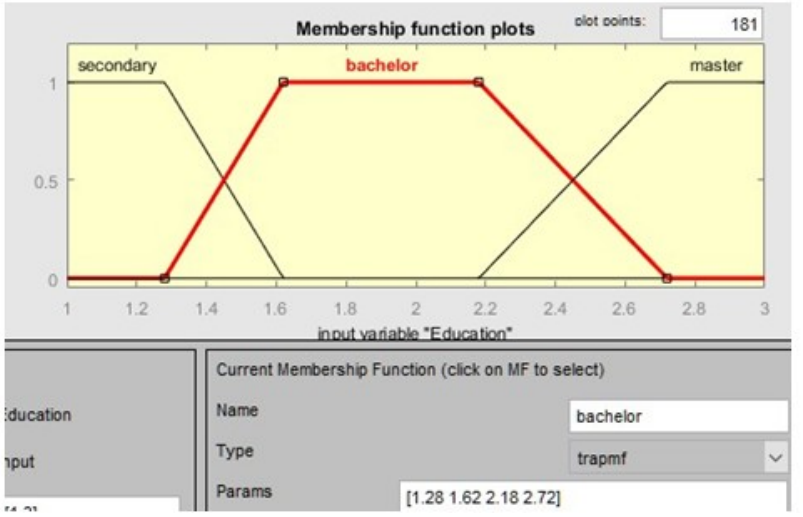

c)
Moreover, the values of the sets are in the range $[0 ; 1] \&[1 ; 3]$.

The use of trapezoidal membership functions lies in the fact that the calculation uses the definition of fuzzy numbers. This is a form of analytical approximation using (LR) - functions that include the trapezoid functions. From this it follows that fuzzy numbers are determined to perform fuzzy modeling operations.

The constructed membership functions of the input linguistic variables are presented in Fig. 3.

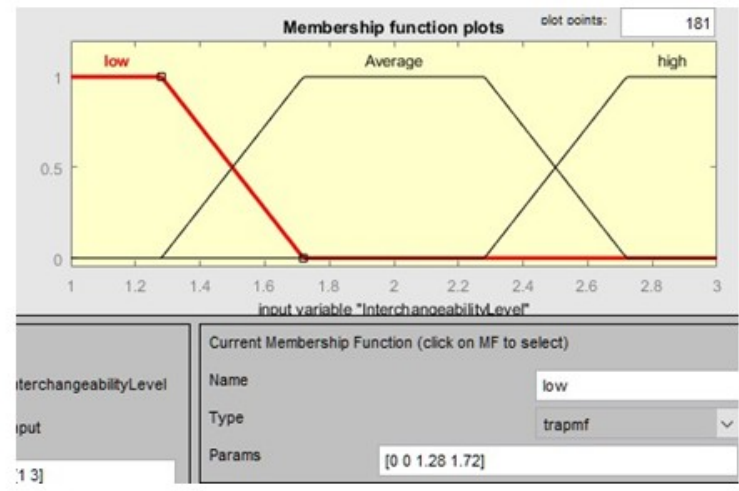

b)

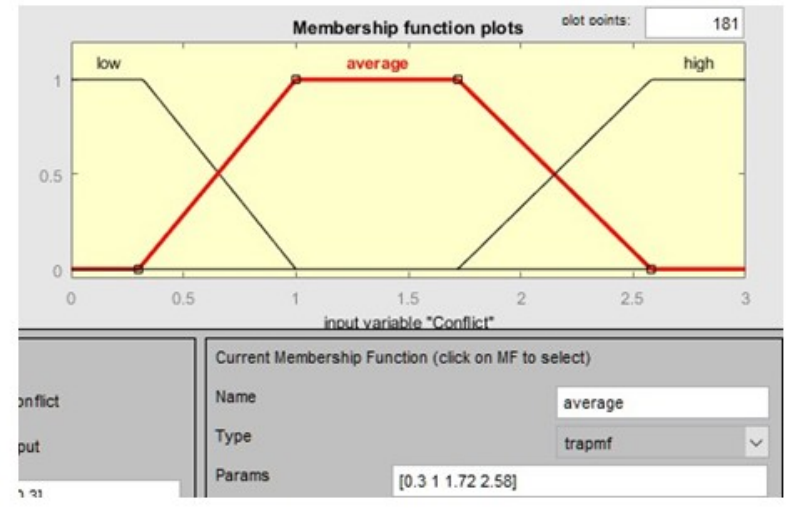

d)

Fig. 3. The membership function of the input linguistic variables: a) "Fulfillment of duties", b) "Interchangeability of posts", c) "Level of education", d) "Conflict".

In the fuzzy inference procedure for managing HR processes, it is necessary to consider the work of employees at all levels of work. The fuzzy inference procedure is implemented in the MATLAB R2017a system, which allowed obtaining the following results of assessing the degree of personnel efficiency.

To perform the procedure, we built the diligence function of the output linguistic variable "assessment of the degree of personnel efficiency", which is presented in Fig. 4.

The simulation results of assessing the degree of personnel efficiency, which is presented in Fig. 5.

The authors of the article propose a solution to the problem of constructing a data analysis method in human resource management and modeling the assessment of the degree of personnel efficiency based on fuzzy sets.

\section{Conclusion}

The following method of data analysis in personnel management is proposed. The method includes four steps. At the first stage, the problem of choosing the analyzed indicators is solved. At the second stage, eight procedures are performed to solve the following problems: to assess the normative or average values of labor productivity, to determine many specialties, to assess the level of education, to assess the levels of enterprise management, to describe a lot of posts, to describe correspondence and job interchangeability, to evaluate additional characteristics of employees, to describe many additional tasks and their characteristics. At the third stage, the procedure for assessing the conformity of the specialty of the post is carried out. At the fourth stage, the procedure for constructing membership functions based on the theory of fuzzy sets is performed. The fuzzy inference procedure is implemented in the MATLAB R2017a system, which made it possible to assess the degree of personnel efficiency.

Prospects for the application of the method and 
procedures of fuzzy modeling in human resource management are the expansion of approaches and the application of cloud computing models.

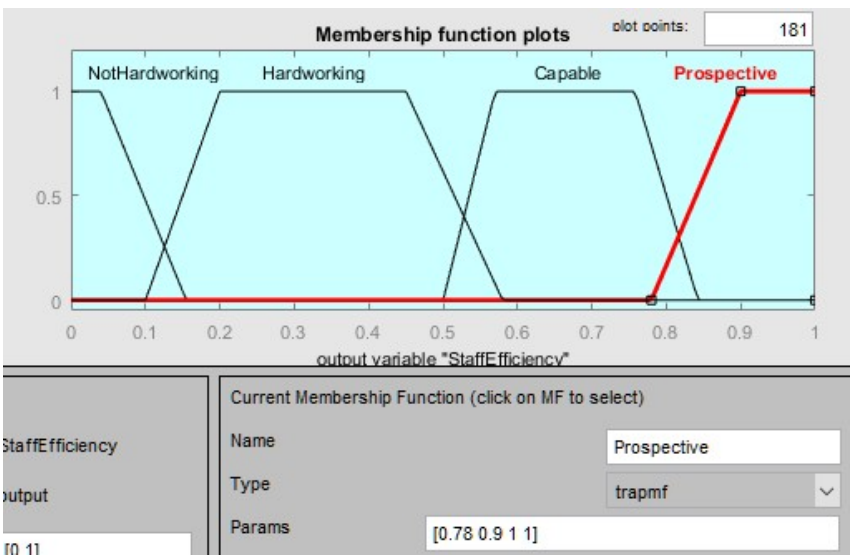

Fig. 4. The membership function of the output linguistic variable "assessment of the degree of personnel efficiency".

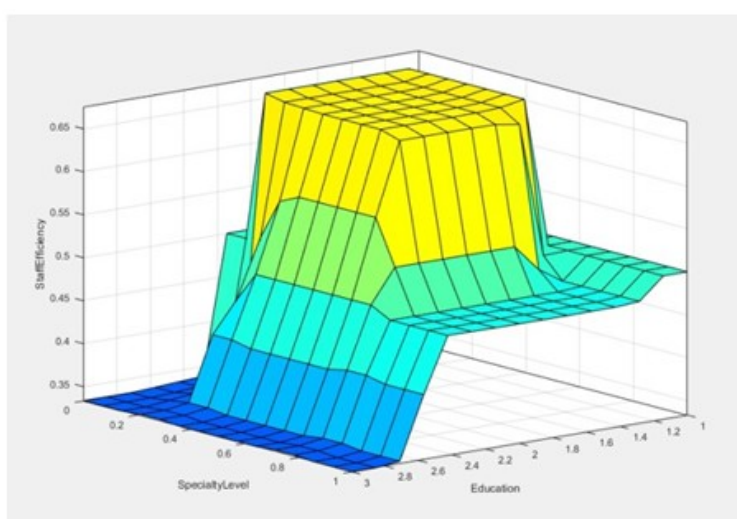

a)

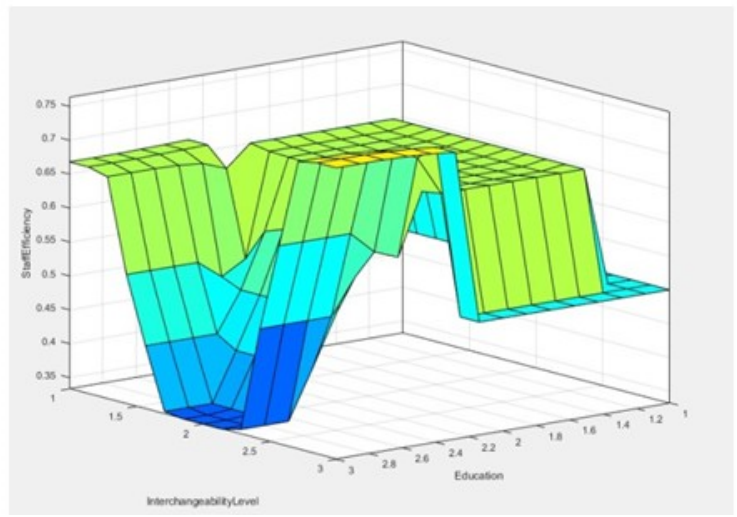

c)

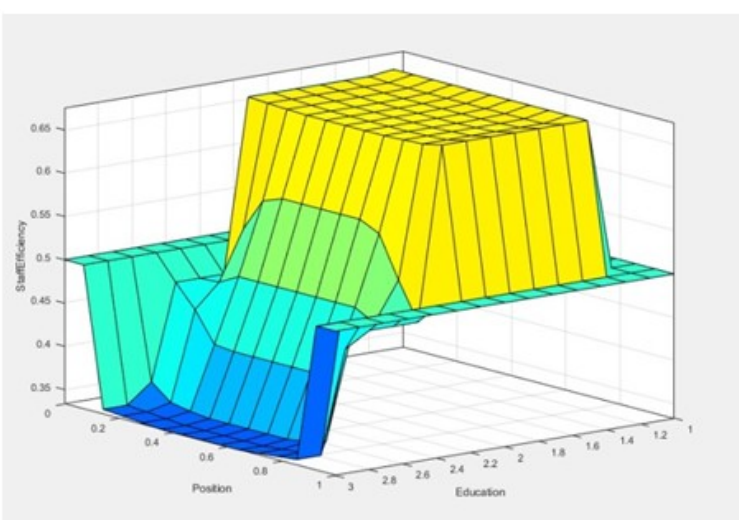

b)

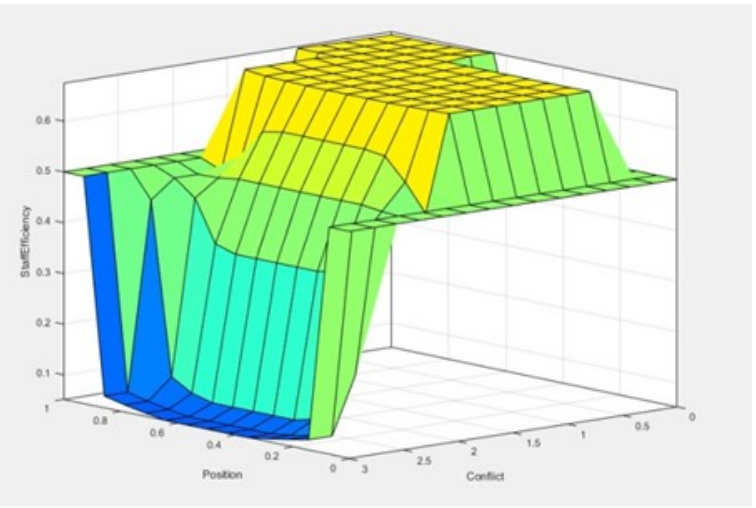

d)

Fig. 5. Modeling the assessment of the degree of personnel efficiency: a) the level of importance of the specialty and education, b) the level of fulfillment of duties and education, c) the level of interchangeability of posts and education, d) the level of fulfillment of duties and conflict.

\section{References}

1. K. Schwab (ed.), The Fourth Industrial Revolution (World Economic Forum, Cologny/Geneva, 2017)

2. S. Ivanov, Modeling Company Sales Based on the Use of SWOT Analysis and Ishikawa Charts. CEUR Workshop Proceedings 2422 (2019)
3. Yu. Lysenko, V. Petrenko, O. Bogatov, V. Skobelev, Reytingovoye upravleniye ekonomicheskimi sistemami (Yugo-Vostok, Donetsk, 1999)

4. V. Helman, Ye. Makazan, A. Buriak, Personnel development as pledge of the success of enterprise, Bulletin Zaporizhzhia national university. Economic 
sciences 3 (2019). doi:10.26661/2414-0287-2019-343-18

5. Br.E. Becker, M.A. Huselid, Strategic Human Resources Management: Where Do We Go from Here? Journal of Management 32, 6 (2006)

6. M.A. Huselid, The Impact of Human Resource Management Practices on Turnover, Productivity, and Corporate Financial Performance. Academy of Management Journal 38, 3 (1995)

7. J. Pfeffer, J.F. Veiga, Putting People First for Organizational Success, Academy of Management Executive 13, 2 (1999)

8. Br.E. Becker, M.A. Huselid, D. Ulrich, Six Key Principles for Measuring Human Capital Performance in Your Organization (working paper, School of Management and Labor Relations, Department of Human Resources Management, Rutgers, State University of New Jersey, 2002)

9. D.R. Briscoe, R.S. Schuler, L. Claus, International Human Resource Management, 3rd edn. (Routledge, New York, 2009)

10. R.S. Schuler, P.S. Budhwar, G.W. Florkowski, International Human Resource Management, in Handbook for International Management Research, ed. B.-J. Punnett, O. Shenkar (University of Michigan Press, Ann Arbor, 2004)

11. S. Gottwald, Universes of Fuzzy Sets and Axiomatizations of Fuzzy Set Theory. Part I, Model-Based and Axiomatic Approaches. Studia Logica 82, 211-244 (2006). doi:10.1007/s11225006-7197-8

12. D. Mukhamediyeva, Razrabotka nechetkikh modeley zadach prinyatiya resheniy (Developing of Fuzzy Models of Decision-making Tasks). (Palmarium Academic Publ., 2014)

13. W. Siler, J. Buckley, Fuzzy Expert Systems and Fuzzy Reasoning (Wiley Interscience, Birmingham, 2005) 